\title{
The IRSN's earliest assessments of the Fukushima accident's consequences for the terrestrial environment in Japan
}

\author{
D. CHAMPION, I. KORSAKISSOK, D. DIDIER, A. MATHIEU, D. QUÉLO, \\ J. GROELL, E. QUENTRIC, M. TOMBETTE, J.-P. BENOIT, O. SAUNIER, \\ V. PARACHE, M. SIMON-CORNU, M.A. GONZE, PH. RENAUD, B. CESSAC, \\ E. NAVARRO, A.-C. SERVANT-PERRIER
}

(Manuscript received 19 November 2012, accepted 26 November 2012)

ABSTRACT In 2011 the IRSN conducted several assessments of atmospheric radioactive releases due to the Fukushima Daiichi NPP accident (March 11, 2011) and of their impact on Japan's terrestrial environment. They were based on the IRSN's emergency management tools and on the abundant information and technical data gradually published in Japan. According to these assessments, the main release phase lasted from March 12 to 25, 2011 and impacted Japanese land in two events, the first on 15 and 16 March, in which the main radioactive deposits were formed, and the second from March 20 to 23, which was less significant. The highest amounts of radioactive deposits were found in an area extending upwards of several tens of kilometers northwest of the plant. Lower amounts were discontinuously scattered in an area extending up to over $250 \mathrm{~km}$ away. Initially composed mainly of short-lived radionuclides, the deposits' activity sharply decreased in the subsequent weeks. Since the summer of 2011, cesium-134 and cesium-137 have become the residual deposits' main components. According to IRSN estimates, in the absence of protection, the doses due to exposure to the radioactive plume during the atmospheric release phase may have been potentially higher for people who remained in coastal areas up to several tens of kilometers north and south of the damaged plant. Thereafter, people living up to $50 \mathrm{~km}$ northwest of the plant, outside the $20-\mathrm{km}$ emergency evacuation zone, were potentially most vulnerable to residual radioactive deposits over time.

Keywords: Fukushima NPP accident / source term / atmospheric dispersion / radioactive deposit / dose assessment

This article summarizes the earliest assessments performed by the IRSN in the year following the Fukushima Daiichi accident on March 11, 2011. They involve the atmospheric radioactive releases due to the accident and their impact on the terrestrial environment. The assessments, which began in the emergency phase and continued throughout 2011, are based on modeling tools available at the IRSN Technical Crisis Center and data published in Japan, in particular on the radioactive deposits and dose rate measurements.

IRSN, Radiation Protection / Environment / Waste / Crisis Department, BP 17, 92262 Fontenay-aux-Roses, France. 
Evaluating the accident's impact on the terrestrial environment is a complex task, due to gaps of data and inaccuracies, particularly with regard to the accident phase and the subsequent weeks. The accident, which damaged three reactors, led to episodic, short-lived atmospheric releases, making it particularly difficult to reconstruct the sequence of events. The many measurement campaigns that have taken place since late March 2011 seem to have provided an increasingly accurate picture of residual contamination in the land environment, but the releases and their earliest consequences must be reconstructed in order to assess the hazards to which the population may have been exposed after the fact.

Analyzing the accident's consequences is also complicated because a release phase resulting in an immediate risk of exposure to the radioactive plume (external exposure and by inhalation) overlapped with a deposit phase that began growing in significance on 16 March, when the releases were continuing.

\section{Atmospheric dispersion of releases and exposure of the population to the radioactive plume}

\subsection{Assessment of atmospheric releases during the accident}

\section{Method and data used}

The Fukushima accident led to multiple radioactive atmospheric releases due to serious damage to the nuclear fuel in reactors 1,2 and 3 , which were no longer being cooled after the tsunami struck the plant on March 11, 2011. Most of the releases were deliberately discharged to ease pressure on the reactors' containment walls. Explosions of hydrogen released into the open air accompanied some of them, seriously damaging the buildings where they occurred.

The IRSN mainly based its earliest (unpublished) estimates of atmospheric releases, conducted on March 12, 2011, on knowledge about the inventory of radionuclides in the reactors and on their behavior in the event of a meltdown; given the lack of accurate information on the damaged facilities' actual condition, they were rough estimates. Then the IRSN sought to establish an increasingly complete picture of the releases based on information from various sources in Japan. It published an estimate of the atmospheric releases due to the accident for the first time on March 22, 2011 (IRSN, 2011) based on an assessment of the condition of the three reactors involved (understanding of the situation, condition of the cooling systems, etc.), which took into account information published in Japan on the dose rate measurements made at the plant site and on voluntary releases of gas from the reactors' containment walls to protect them from the risk of damage by overpressure. 


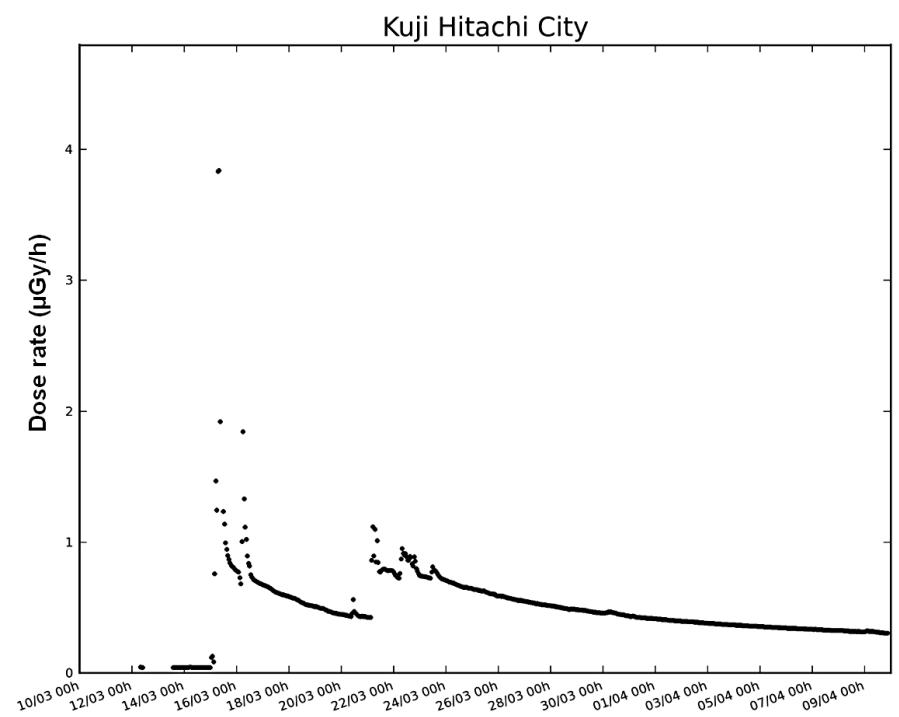

Figure 1 - Ambient dose rate (radioactive plume and fallout) in Kuji Hitachi City (about $110 \mathrm{~km}$ south of Fukushima Daiichi NPP) measured by a monitoring station of the SPEEDI Network, from 10/03 to 10/04, 2011.

After the crisis period in spring 2011, the IRSN fine-tuned its assessments using the higher amount of environmental data available and atmospheric dispersion models on the local (model pX) and regional scales (model ldX) to interpret them (Korsakissok et al., 2012; Corbin and Denis, 2012; Saunier et al., 2012; Mathieu et al., 2011). The dose rate measurements, mostly from Japan's SPEEDI automated monitoring stations network, were the most plentiful. However, the earthquake and tsunami knocked out Fukushima prefecture's SPEEDI detectors during the release period, and only data from the most distant detectors, located up to several hundred kilometers away, could be used by comparing them with the model's results on the regional scale. As an example, Figure 1 below illustrates the change in the dose rate between March 10 and April 10, 2011 as measured by a SPEEDI detector in Kuji Hitachi (Ibaraki prefecture).

The IRSN used dose rate measurements that were recorded in each prefecture, particularly Fukushima, and published by the $\mathrm{MEXT}^{1}$, to compare the results of local models (less than $100 \mathrm{~km}$ ) with environmental measurements.

1 Ministry of Education, Culture, Sports, Science \& Technology - Japan http://radioactivity.mext.go.jp/en/. 
The release kinetics and attribution of release events to the various reactors were based on the interpretation of peak dose rates observed at the edge of the Fukushima Daiichi nuclear power plant site. Prior to March 17, deliberate containment venting, sometimes accompanied by hydrogen explosions, caused the releases. The timeline is now well known. It is harder to connect releases occurring after March 17 to specific events at the site and to situate them in time. Given the extent of damage to the facilities and the severe contamination of the nuclear site, atmospheric releases had to continue after March 2011 but at a level that was much lower and harder to detect in the environment.

To more accurately determine when the release events took place, the IRSN developed a "tracer" method, which involves modeling the dispersion of unit "tracer" releases over a three-hour period, i.e.124 tracer releases for the period from 0:00 on March 12, 2011 to 0:00 on March 26, 2011 and correlating the passage of the plume resulting from that dispersion with peak dose rates measured by detectors at various places in Japan. In the context of the Fukushima accident, this method is only valid for releases that had a measurable impact on the land environment but gives no indication for the releases that dispersed above the sea, where there are no detectors.

Very few measurements of volumetric activity in the air performed in Japan have been made public. The only findings of any real interest (because they span the entire period of significant releases) come from the stations of TokyoShinjuku, $250 \mathrm{~km}$ south-southwest of the plant; Tsukuba (Ibaraki prefecture), around $170 \mathrm{~km}$ from the plant in the direction of Tokyo; and Takasaki (Gunma prefecture), $250 \mathrm{~km}$ southwest of the plant. However, since these monitoring stations are in the same area, the information they provide is redundant, except for the measurements of noble gases, which only the Takasaki detector took.

\section{Results}

Table I below presents the IRSN's estimates of atmospheric releases, comparing them with the estimates the NISA ${ }^{2}$ published in Japan in June 2011 (NISA, 2011).

The IRSN's work in 2011 (Korsakissok et al., 2012; Corbin and Denis, 2012; Saunier et al., 2012) also helped to estimate the distribution over time of the various release events due to the accident (Fig. 2).

\section{Discussion}

These estimates are still considered provisional and inaccurate. In particular, the distribution of releases by reactors estimated by the IRSN is uncertain for the

2 Nuclear and Industrial Safety Authority - Japan. 
TABLE I

Assessment of activities (in petabecquerel - PBq) of the main categories of radionuclides released into the atmosphere during the Fukushima NPP accident, performed by the IRSN during the emergency phase (IRSN-CTC) and afterward (2011 complementary studies) and by the NISA.

\begin{tabular}{ccccc}
\hline $\begin{array}{c}\text { Category of } \\
\text { radionuclides }\end{array}$ & $\begin{array}{c}\text { IRSN-CTC } \\
\text { prognosis on } \\
\text { March 12, 2011 }\end{array}$ & $\begin{array}{c}\text { IRSN-CTC } \\
\text { estimate on } \\
\text { March 22, 2011 }\end{array}$ & $\begin{array}{c}\text { IRSN } \\
\text { complementary } \\
\text { study 2011 }\end{array}$ & $\begin{array}{c}\text { NISA } \\
\text { estimate June } \\
\text { 2011 }\end{array}$ \\
\hline rare gases & $3400 \mathrm{PBq}$ & $2080 \mathrm{PBq}$ & $6550 \mathrm{PBq}$ & $\begin{array}{c}11000 \mathrm{PBq} \\
(\mathrm{Xe}-133)\end{array}$ \\
$\begin{array}{c}\text { iodine } \\
\text { isotopes } /{ }^{131} \mathrm{I}\end{array}$ & $1300 \mathrm{PBq}$ & $182 \mathrm{PBq} / 90 \mathrm{PBq}$ & $408 \mathrm{PBq} / 197 \mathrm{PBq}$ & $162 \mathrm{PBq} / 160 \mathrm{PBq}$ \\
$\begin{array}{c}\text { cesium } \\
\text { isotopes } /{ }^{137} \mathrm{Cs}\end{array}$ & $90 \mathrm{PBq}$ & $26 \mathrm{PBq} / 10 \mathrm{PBq}$ & $58 \mathrm{PBq} / 21 \mathrm{PBq}$ & $33 \mathrm{PBq} / 15 \mathrm{PBq}$ \\
telluride isotopes & $500 \mathrm{PBq}$ & $76 \mathrm{PBq}$ & $145 \mathrm{PBq}$ & $5 \mathrm{PBq}$ \\
\hline
\end{tabular}

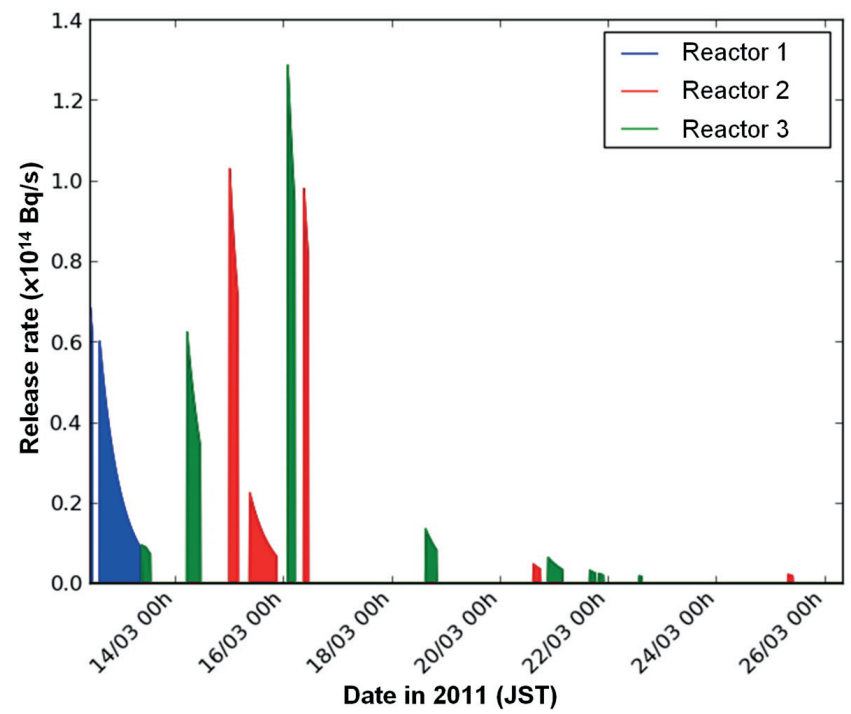

Figure 2 - (Color online) Evolution of release rate for all the radionuclides released into the atmosphere during the Fukushima accident (blue: reactor 1; red: reactor 2; green: reactor 3) (IRSN assessment, 2011).

above-mentioned reasons, especially the lack of measurements over the sea. For example, according to these estimates, reactor 3 seems responsible for the biggest releases ( $65 \%$ of the cesium isotopes and $62 \%$ of the iodine isotopes). However, given the damage to reactor 2's containment, most of the atmospheric discharges may have come from the latter but the IRSN's studies do not make it possible to demonstrate this. In fact, with the exception of the earliest releases, attributing them to one or the other reactor is a matter of guesswork. 
The estimate the NISA published in June is mainly based on analysis of the events and phenomena at the stricken facilities and gives scant consideration to the radioactivity measurements in the environment. Despite the different approaches, the results are generally consistent with respect to the order of magnitude. The IRSN's first estimate, on March 12, 2011, early in the emergency, is clearly inaccurate and tends to overestimate the assumed releases except for the rare gases. The releases of radioactive iodine isotopes (mainly iodine-131 and iodine-132) are estimated at several hundred $\mathrm{PBq}$, corresponding to approximately $10 \%$ of the iodine releases due to the Chernobyl accident (IAEA, 2006). The releases of radioactive cesium isotopes (mainly cesium-137 and cesium-134) are estimated at several tens of PBq, i.e. one-third of the releases at Chernobyl. Releases of rare gases, mostly short-lived (5.3 days) xenon-133, were probably around $10000 \mathrm{PBq}$, the same level as those at Chernobyl. A wider gap is observed for estimates of telluride releases (mainly telluride-132).

According to the IRSN estimates, releases of other radionuclides probably amount to a total activity of $28 \mathrm{PBq}$. Due to their short half-lives (a few minutes for some) or their very low activities in the atmospheric releases, not all the radionuclides have been detected in Japan's environment. Those that have been measured in fallout include barium-140, estimated at $1.12 \mathrm{PBq}$, strontium-89 $(0.043 \mathrm{PBq})$ and strontium-90 (0.003 PBq). These radionuclides, which are less volatile and could have mainly remained inside the damaged facilities, were released in smaller amounts than those mentioned above; however, estimates of releases of these radionuclides remain inaccurate because not enough measurements or data on the stricken reactors' actual condition exist. That is also the case of plutonium and other transuranium elements, whose presence in the environment due to the accident was found in trace amounts northwest of the Fukushima Daiichi plant (MEXT, 2011a). However, those traces are hard to distinguish from those of residual plutonium fallout from atmospheric nuclear tests in the 1960s.

\subsection{Modeling the dispersion of atmospheric releases in Japan}

\section{Tools and methods}

The IRSN's $\mathrm{C}^{3} \mathrm{X}$ calculation platform codes were used to model atmospheric dispersion of releases on the local and regional scales. $\mathrm{C}^{3} \mathrm{X}$ is the operational software suite used to assess consequences in emergency situations. Developed by the IRSN, it is based on two atmospheric dispersion codes:

- a Gaussian puff model named pX (Soulhac and Didier, 2008) which is dedicated to short-range issues (up to $80 \mathrm{~km}$ );

- a Eulerian model named ldX (Quélo et al., 2007) which covers upper scales. 
$\mathrm{C}^{3} \mathrm{X}$ provides post-treatment tools which produce reports and maps of consequences anywhere the accident took place.

The earliest assessments, performed in March 2011 and regularly updated based on fresh available data, were highly inaccurate on the local scale (less than several tens of kilometers around the site) due to insufficient data on release conditions and local weather; however, better meteorological data made them satisfactory on the regional (several hundred to thousands of kilometers) and global scales (Mathieu et al., 2011).

Throughout 2011, additional work based on abundant environmental data made it possible to obtain a more realistic estimate of the dispersion's consequences, particularly on the local scale and in terms of doses potentially received by the population exposed to the radioactive plume (see below).

The IRSN used its $\mathrm{C}^{3} \mathrm{X}$ platform's three-dimensional $l d X$ model to model atmospheric dispersion on a regional scale. The model has the same spatial resolution as the meteorological data used: around $12 \mathrm{~km} . l d X$ is a Eulerian model, meaning that the calculated volumetric activity (as well as the deposit) is homogenous on the scale of a calculation grid (elementary volume of the atmosphere taken into account for the model). Thus, $l d X$ results can be compared with measurements only when the plume's width has become noticeably wider than the grids' size. In practice, $l d X$ results are considered usable at a distance of approximately five to eight grids from the release point, i.e., in the case of Japan, around 50 to $80 \mathrm{~km}$. Below this distance, the model cannot correctly estimate the steep gradients of concentration of radionuclides in the air, which still exist near the release point.

For the modeling of the atmospheric dispersion of releases on a local scale (in an 80-km radius around the Fukushima Daiichi plant; see Figs. 3, 5, 7 and 8), the IRSN used its $C^{3} \mathrm{X}$ calculation platform's $p X$ model, adapted to this scale. This Gaussian puff model takes account of the wind's spatial heterogeneity throughout its area of calculation. Various sensitivity tests were performed before Pasquill's standard deviations were chosen for this model (Korsakissok et al., 2012).

The reliability of the findings obtained with $p X$ or $l d X$ atmospheric dispersion models largely depends on the quality of the data about the accident's releases and meteorological conditions.

During the Fukushima emergency, the IRSN lacked the necessary local data on the meteorological fields in the region of the stricken power plant. Furthermore, 
the shape of the environment near Fukushima made it difficult to model wind patterns. Seafront effects and effects due to a complex orography (valleys and mountains) resulted in highly variable, hard-to-simulate wind direction. Work that the IRSN later carried out in collaboration with Météo France showed that some meteorological events were very hard to model, even after the fact. A case in point is the event of release towards Japanese land on March 15-16, for which meteorological models failed to reproduce the wind directions observed. Likewise, the wind direction models were fairly inaccurate in the case of wind blowing along the Japanese coast, particularly southward. These problems also concerned simulations on the regional scale, but they had a less noticeable effect than those on the local scale, where the plume was highly concentrated, with high concentration gradients.

\section{Results}

The models of atmospheric dispersion of releases due to the Fukushima accident have helped to reconstruct the main air contamination events in Japan.

The earliest releases, which occurred between March 12 and 14, mainly dispersed northward along Honshu Island's east coast before shifting to the northeast and east above the Pacific (Fig. 3). Thus, the first releases, which occurred when the reactor 1 building exploded on March 12, were only detected in Minamisoma, approximately $30 \mathrm{~km}$ north of the damaged plant, where the dose rate values measured were consistent with those the model obtained (Fig. 4).

On March 15 and 16, reactor 2's releases dispersed inland, when the meteorological conditions were quickly shifting (Fig. 5). In the absence of rain, the fallout released in the early hours of March 15 drifted southward along the coast.
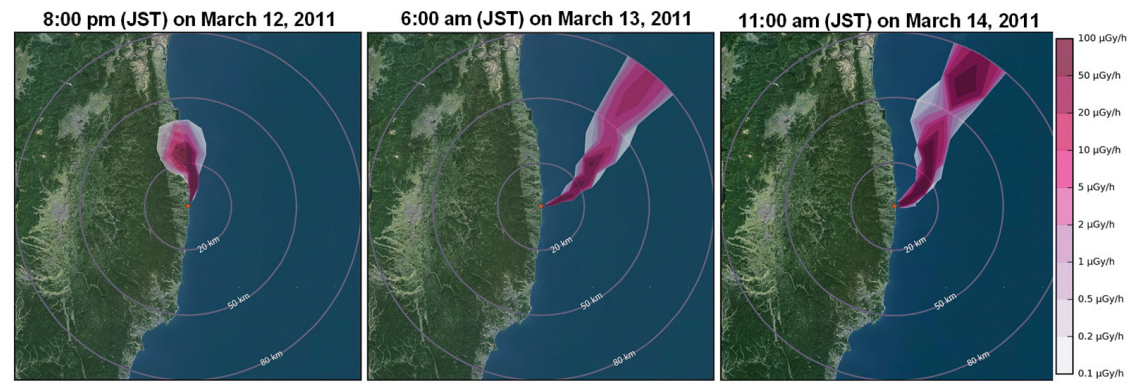

Figure 3 - (Color online) Model of the ambient dose rate due to atmospheric dispersion of releases from the Fukushima accident between March 12-14 (excluding the contribution of radioactive fallout - the IRSN's pX model on the local scale). 


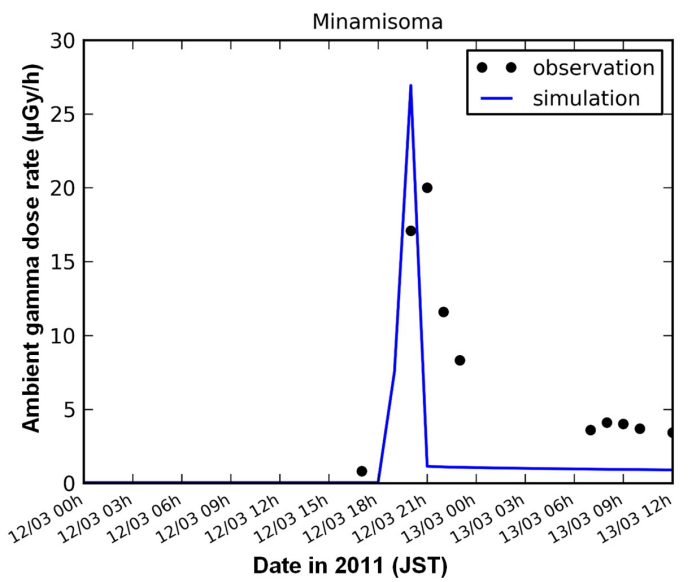

Figure 4-(Color online) Ambient dose rate (radioactive plume and fallout) in Minamisoma (about 30 km north of Fukushima Daiichi NPP): comparison between measured values (black dots) and simulation with the $\mathrm{pX}$ model (blue line).
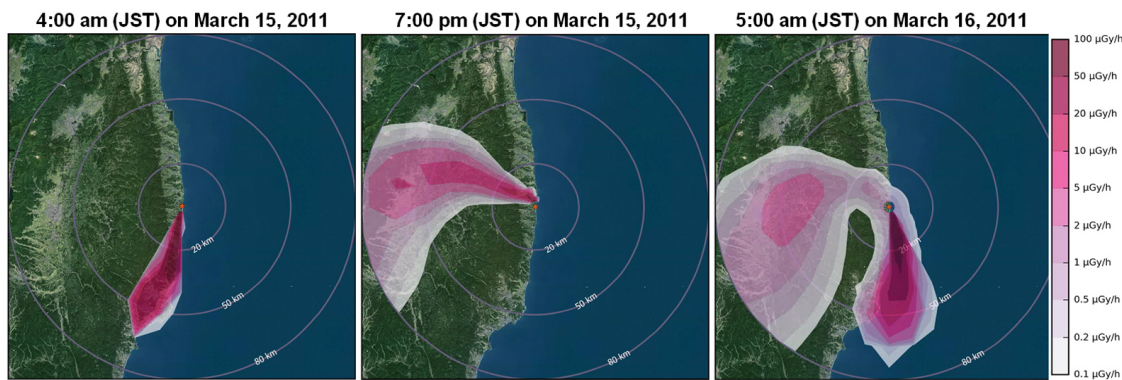

Figure 5 - (Color online) Model of the ambient dose rate due to atmospheric dispersion of releases from the Fukushima accident on March 15 and the morning of March 16 (excluding the contribution of radioactive fallout - the IRSN's $\mathrm{pX}$ model on the local scale), illustrating the first contamination event on Honshu Island.

A short distance away, for example in Iwaki, the dose rates estimated by the model were significantly higher than those measured in the same town during the course of this period (Fig. 6). This discrepancy could be due to an effect involving the releases' discharge height — a sensitive parameter on this scale — or to a real wind direction different from the model, blowing the plume more towards the Pacific. These uncertainty factors are all the more sensitive since the meteorological situation was only slightly dispersive at the time and engendered a very thin plume. But further away, the values estimated with the $l d X$ model were consistent with the findings provided by the SPEEDI network's monitoring stations in Ibaraki prefecture. The releases emitted on the evening of March 15 and during the night 

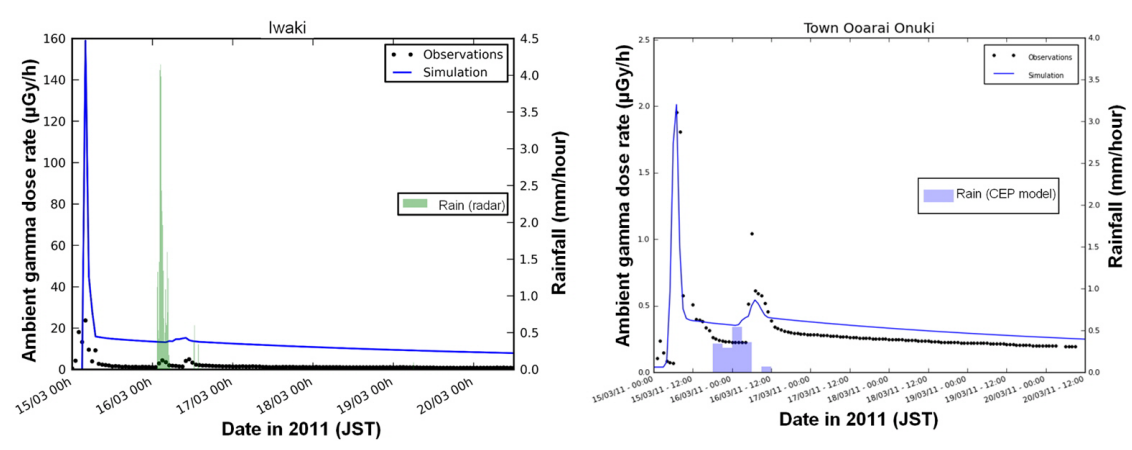

Figure 6 - (Color online) Ambient gamma dose rate (radioactive plume and fallout) in Iwaki (about $40 \mathrm{~km}$ south of Fukushima Daiichi NPP) and in Ooarai (Ibaraki prefecture, about $100 \mathrm{~km}$ south): comparison between measured values (black dots) and simulation (blue line) with the $\mathrm{pX}$ model (Iwaki) or ldX model (Ooarai).
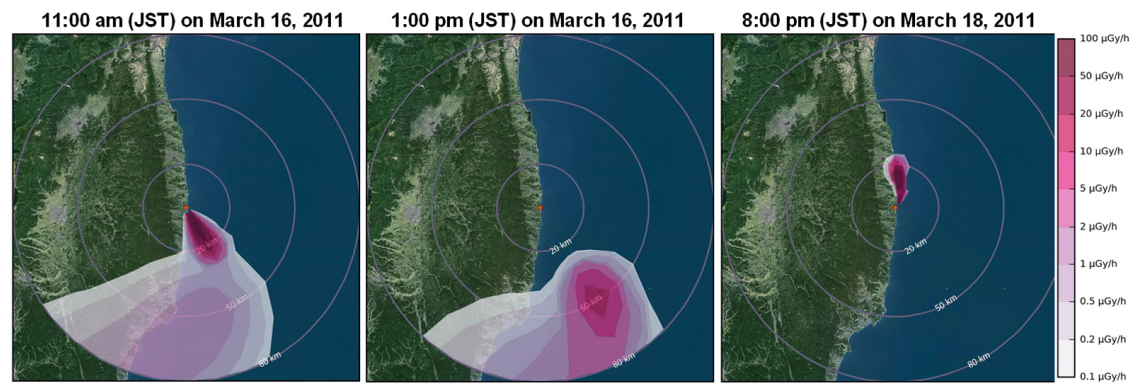

Figure 7 -(Color online) Model of the ambient dose rate due to atmospheric dispersion of releases from the Fukushima accident on March 15 and the morning of March 16 (excluding the contribution of radioactive fallout - the IRSN's pX model on the local scale), illustrating the first contamination event on Honshu Island.

of March 15-16 drifted northwest before shifting southwest when heavy rain and snow fell, primarily between 9 p.m. and midnight (Fig. 11). Early on the morning of March 16, the releases again dispersed southward.

On March 16 and the following days the releases, which were less frequent and estimated to be in smaller amounts, dispersed eastward over the Pacific, away from most of Japan's land (Fig. 7). 

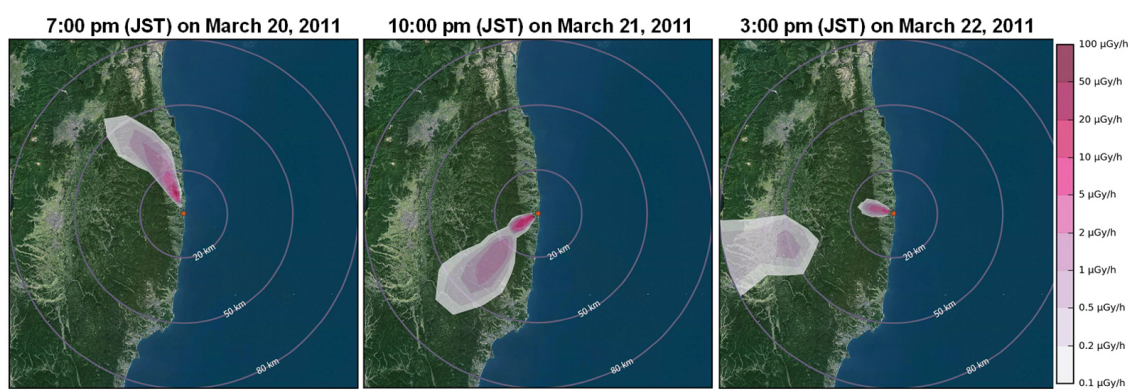

Figure 8 - (Color online) Model of the ambient dose rate due to atmospheric dispersion of releases from the Fukushima accident between March 20-22 (excluding the contribution of radioactive fallout - the IRSN's $\mathrm{pX}$ model on the local scale), illustrating the second contamination event on Honshu Island.

Between the afternoon of March 20 and March 23, the episodic releases were again dispersed above Japanese land (Fig. 8). Although less significant than the March 15-16 event, this new terrestrial event caused the main radioactive deposits observed in the Tokyo metropolitan area, where rainfall was heavy at the time.

After March 23, contaminated air masses drifted out over the Pacific and subsequent releases were too small to bring about a significant increase in radioactivity in the terrestrial environment.

\subsection{Estimate of doses potentially received by the population during the release phase}

\section{Hypotheses retained}

In order to identify the potentially most-exposed people during the main atmospheric release phase, the IRSN assessed the doses that an unprotected (in other words, remaining outside) one-year-old child would have received assuming that he stayed in the same place from March 12 (the date of the earliest releases) to midnight on March 25 (the last significant releases). This exposure scenario is obviously not realistic but helps to identify the areas where emergency protection actions should have been taken first. The IRSN usually applies this "envelope" approach in order to forecast an accident's potential dosimetric consequences with the aim of recommending reasonably cautious protective actions in a highly uncertain context. The age group chosen for this assessment (one-year-old) is the one that is the most sensitive to exposure to radioactive releases, particularly radioactive iodine isotopes (in terms of doses received by the thyroid). 
To assess these doses, the IRSN considered the three main exposure pathways during the release phase:

- external exposure to gamma radiation emitted by the radioactive plume;

- internal exposure through inhalation of airborne radionuclides;

- external exposure to gamma radiation emitted by radioactive deposit on the ground's surface, which gradually forms depending on rainfall and the radioactive plume's trajectories.

The dose likely to have been received through ingestion of contaminated food was not taken into account because it is not decisive in the emergency protection strategy (shelter or evacuation, distribution of stable iodine).

\section{Results}

The maps in Figure 9 show, respectively, the effective dose's geographic distribution and the equivalent thyroid dose potentially received during the release phase according to the hypotheses described above, calculated on the local scale with the $p X$ model.

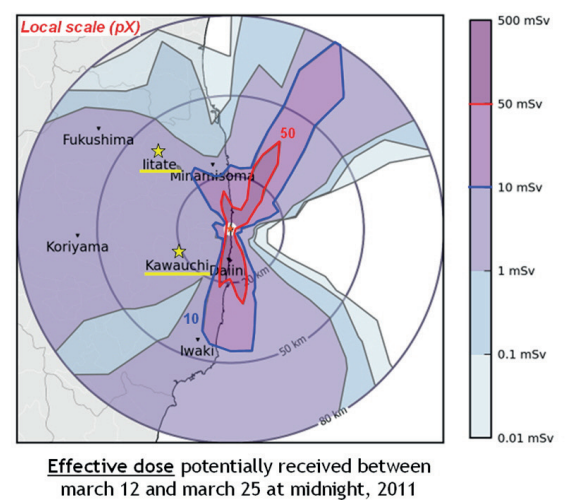

Figure 9 - (Color online) Maps of the effective doses (left) and equivalent thyroid dose (right) potentially received by an unprotected 1-year-old child during the Fukushima accident's release phase (IRSN pX model, local scale).

The estimates show that the ocean is probably where the atmospheric releases had the greatest dosimetric impact. Of course, they are virtual doses because no human lives permanently in this environment. Moreover, the lack of ambient radioactivity measurements in the ocean at the time the releases occurred makes these theoretical doses particularly inaccurate and probably overestimated. 
On land, the coast immediately north and south of the stricken power plant probably received most of the highest doses. Based on this model, an effective dose exceeding $10 \mathrm{mSv}$ (the intervention level in France for population sheltering) could have been received up to approximately 40 kilometers to the south, assuming a permanent presence outdoors; effective doses over $50 \mathrm{mSv}$ (the intervention level in France for emergency evacuation) could only have been reached within a $20-\mathrm{km}$ radius, corresponding to the area evacuated from March 12. Theoretical values of the equivalent thyroid doses exceeding $50 \mathrm{mSv}$ (the intervention level in France for intake of stable iodine tablets) and $100 \mathrm{mSv}$, respectively, could have been received in Iwaki, up to approximately 60 and 40 kilometers south of the plant; they correspond to a release from reactor 2 occurring between midnight and 5 a.m. on March 15, when the wind direction was south. However, as indicated above, the atmospheric dispersion model of the releases on the morning of March 15 tends to overestimate the radiological impact in this area because of uncertainty about the discharge height and wind direction. It is therefore uncertain whether Iwaki's population, located outside the emergency evacuation zone, was exposed to such high dose levels.

It should be pointed out that the calculated doses relying on results of anthroporadiometric measurements of French citizens who had been staying within a $60-\mathrm{km}$ radius of the Fukushima Daiichi plant at the time of the releases are clearly lower than those estimated above, based on model and "envelope" hypotheses; the highest values were observed in a person who lived in Iwaki until March 15, with an effective dose lower than $0.1 \mathrm{mSv}$ and an equivalent thyroid dose of $1.4 \mathrm{mSv}$. The envelope scenario chosen for modeling the doses and uncertainty about the releases' atmospheric dispersion in the southern sector on the local scale, as indicated above, explain these significant differences.

The dose estimates performed by the IRSN show that for the same level of potential dose (effective dose of several $\mathrm{mSv}$, excluding ingestion of possibly contaminated food), there may have been a significant disparity in the various exposure pathways' contributions and the dose kinetics from one place to another during the March 12-25 release phase (Fig. 10).

Kawauchi is representative of the exposure situation during the release phase in the areas west and south and on the coast north (Minamisoma) of the damaged plant:

- most of the effective doses potentially received between March 12 and 25 appear to have resulted from internal exposure by inhalation of radioactive substances (70-80\%, depending on the place) and secondarily from external exposure to dry deposit (15-20\%); 

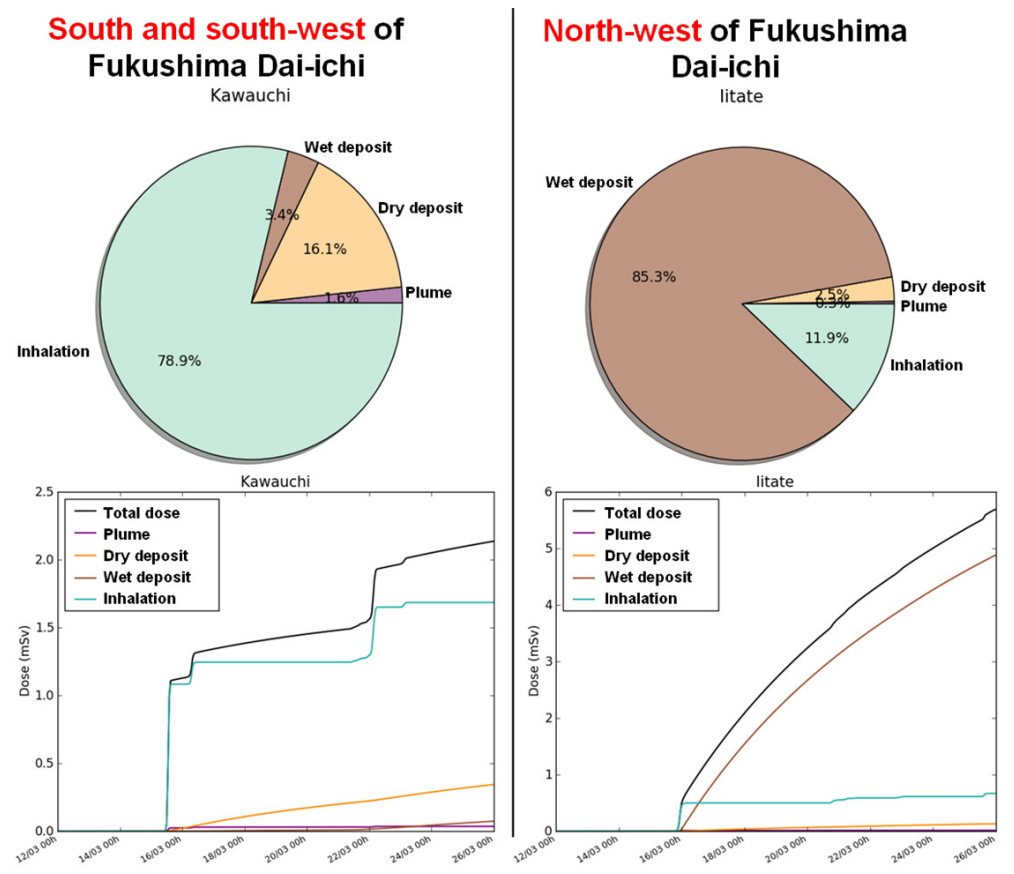

Figure 10-(Color online) Contribution of the exposure pathways and dose kinetics (effective dose, without protection) during the release phase (March 12-25, 2011) in two different locations (Kawauchi and Iitate, shown in Fig. 9) within $40 \mathrm{~km}$ of Fukushima Daiichi (cumulative doses calculated using the $\mathrm{pX}$ model).

- the doses appear to have been received during brief exposure periods (in stages), mainly around March 15-16 (except to the north, where the first exposure occurred on March 12 and 13) and around March 22-23;

- after the release period, exposure due to gamma radiation emitted by the radioactive deposits appears to have continued at more moderate levels.

Litate is characteristic of the exposure situation during the release phase in the areas to the northwest, towards the city of Fukushima:

- most of the effective doses potentially received between March 12 and 25 appear to have resulted from external exposure to wet deposit (around 85\%) and secondarily from internal exposure by inhalation of radioactive substances (around 12\%);

- the doses appear to have been gradually received from March 15 on;

- after March 25, exposure appears to have persisted due to significant deposits. 
The significant differences in dose kinetics and the exposure pathways' respective contributions to the dose are due to differences in the intensity of rainfall at the time of the releases, which were concentrated to the northwest on the night of March 15-16, leading to large radioactive deposits (see below). In these areas, external exposure to radioactive deposits quickly became the main exposure pathway, which persisted long after the release phase.

\section{Formation of radioactive deposits and short-term consequences}

\subsection{Characteristics of radioactive deposits resulting from the Fukushima accident}

\section{Causes of the deposits and geographical distribution}

During the main two events of dispersion of radioactive releases over Japanese land, two complementary processes were at work in depositing some of the aerosols and gaseous iodine isotopes on ground surfaces:

- the formation of dry deposits on all the surfaces in contact with contaminated air (plants, ground, buildings, objects, etc., even inside buildings when interior air is contaminated), due to air turbulence, whatever their nature and direction (horizontal, vertical or reverse);

- the formation of wet deposits in areas where precipitation (rain or snow) took place during the radioactive plume's dispersion. They occur when drops of water carry radioactive particles or soluble gases (iodine) from the air to the ground. They have no impact inside buildings.

On the night of March 15-16, a rain front moving southeast from northwest caused heavy precipitations (rain or snow depending on the elevation) in the Fukushima region, while the radionuclides in air were dispersed in the opposite direction to the northwest and then southward (Fig. 11). This resulted in significant radioactive deposits at distances of up to several tens of kilometers northwest of the Fukushima Daiichi power plant, which caused a lasting increase in the ambient dose rate. The second air contamination event over Honshu Island (from March 22 to 23) also contributed to the accumulation of radioactive deposits, but in smaller amounts and in different areas, where heavy rainfall occurred (the Tokyo metropolitan area, Chiba, Ibaraki, Tochigi and Saitama prefectures).

After the earliest observations in March 2011, the Japanese Ministry of Education, Culture, Sports, Science and Technology (MEXT) coordinated and organized airborne measurement campaigns, which were conducted by the 

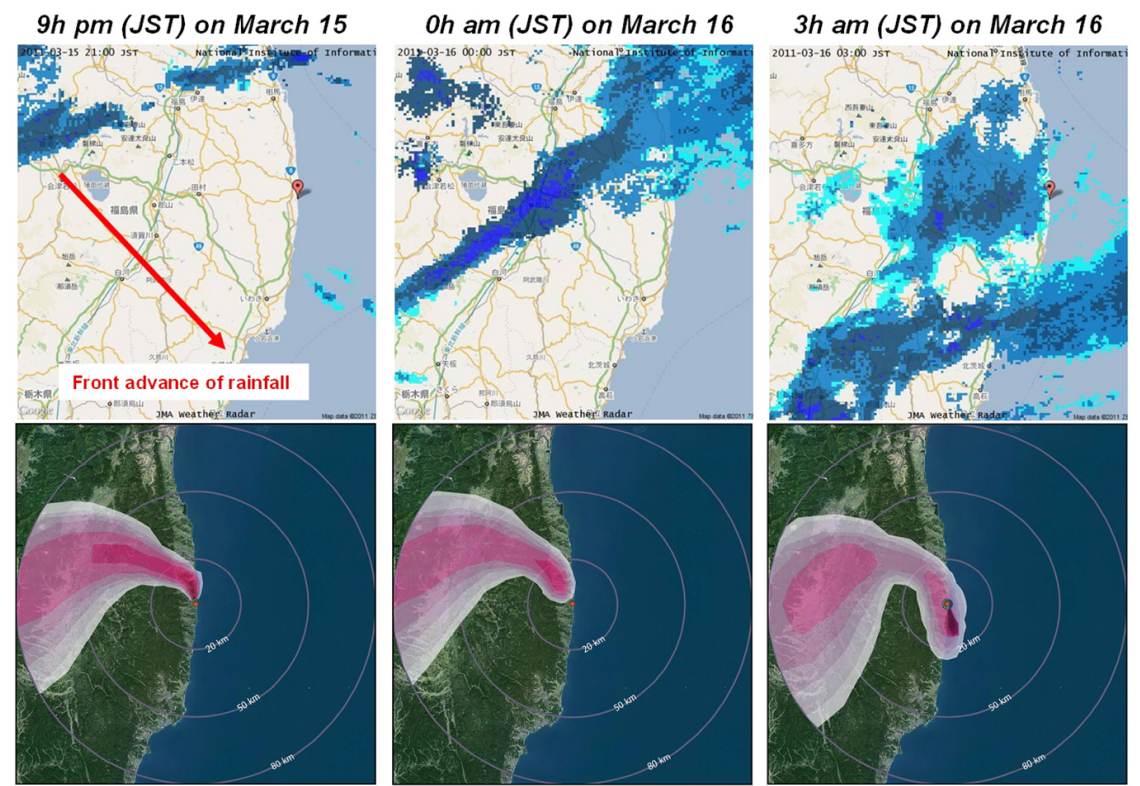

Figure 11 -(Color online) Front advance of rainfall events on the night of March 15 to 16, 2011 (radar measurements; source JMA) in Fukushima prefecture, at the time of dispersion to the northwest of radionuclides released from unit 2 of Fukushima Daiichi NPP (pX model, IRSN).

Japanese Atomic Energy Agency (JAEA) and the Nuclear Technology and Safety Center (NUSTEC) with technical assistance from the United States Department of Energy (US-DOE/NNSA) to gradually map out radioactive deposits. The first three campaigns, which took place from April 6 to 29, May 18 to 26 and May 30 to July 2, focused on an 80-km radius around the Fukushima Daiichi plant. In the summer of 2011, a consortium of Japanese universities under the aegis of the MEXT took soil samples (the top five centimeters) for laboratory analysis that supplemented the airborne campaigns. Their findings provided more information on the deposits and were checked for consistency with those that the airborne campaigns obtained. The maps in Figure 12 illustrate deposits of radioactive cesium isotopes $\left({ }^{134} \mathrm{Cs}+{ }^{137} \mathrm{Cs}\right)$ and the ambient dose rate around the Fukushima Daiichi nuclear power plant (the eastern part of Fukushima prefecture). They show the area where the biggest deposits were observed: above one million $\mathrm{Bq} / \mathrm{m}^{2}$ for the cumulative deposits of cesium-134 and cesium-137 and nearly 30 million $\mathrm{Bq} / \mathrm{m}^{2}$ immediately west of the damaged plant. 


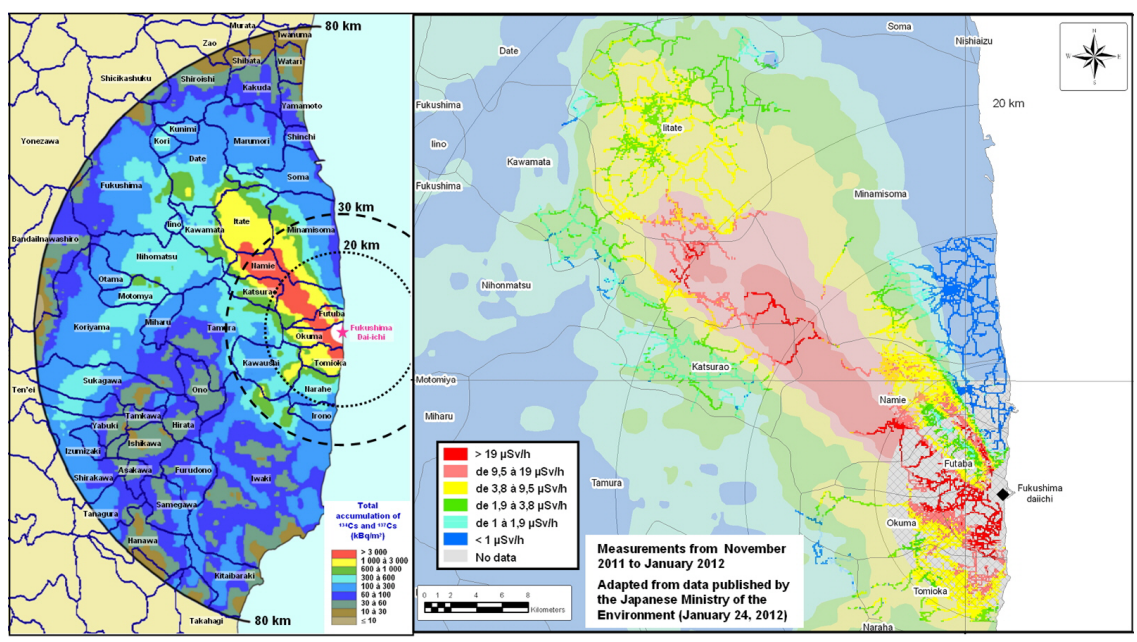

Figure 12 -(Color online) Maps of the main area of radioactive fallout resulting from the Fukushima accident: left, map of the cumulative deposit of cesium-134 and cesium-137 (airborne monitoring - adapted by the IRSN from an original map published by the MEXT (MEXT, 2011 )); right, map of the ambient dose rate (car-borne and field monitoring - adapted by the IRSN from an original map published by the Japanese Ministry of the Environment, February 24, 2012 - http://www.env.go.jp/press).

The maps that the MEXT published in summer and fall 2011 cover northern Honshu Island. They show that smaller but nevertheless significant deposits (several tens to hundreds of thousands of $\mathrm{Bq} / \mathrm{m}^{2}$ ) also formed in areas further away from the Fukushima prefecture, an extension of the main deposition area, and in neighboring prefectures as scattered spots ("leopard spot" pattern) (Fig. 13).

\section{The radioactive deposits' composition}

The maps in Figures 12 and 13 show the contaminated areas' situation nearly a year after the accident, when the radioactive cesium isotopes (cesium-134 and cesium-137) were almost the only deposits left. The situation was very different in the weeks after the accident, when short-lived radionuclides predominated. The graph in Figure 14 shows the evolution in the relative activity of the main radionuclides initially present in the surface deposits in Iitate Maeta, approximately 40 kilometers northwest of the Fukushima Daiichi plant, to illustrate the early situation. It is based on the IRSN's gamma spectrometry analysis of a topsoil sample that the ACRO (the Association for Monitoring Radioactivity in the West) collected in Iitate Maeta on March 31, 2011, by taking into account only the radioactive decay of radionuclides quantified in the sample and considering that the initial deposit 


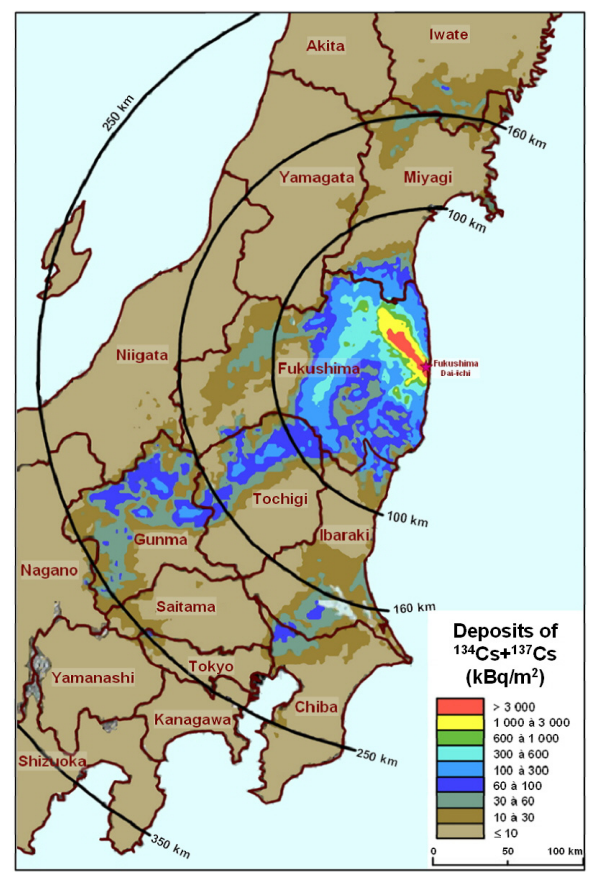

Figure 13 -(Color online) Map of the cumulative deposits of cesium-134 and cesium-137 (converted into the value as of October 13, 2011) in the north of Honshu Island (adapted by the IRSN from an original map published by the MEXT (MEXT, 2011b)).

formed on March 15. The graph also shows a series of ambient dose rate measurements performed during the same period in Namie (Akougi Teshichiro) (data published on the MEXT internet site), $31 \mathrm{~km}$ northwest of the stricken plant, showing decay over the course of time comparable with that of the activity of the topsoil sample collected in Iitate Maeta.

This graph shows that telluride-132/iodine- $132^{3}$ accounted for nearly $49 \%$ of the deposits' activity at first but very quickly disappeared from the environment (less than $5 \%$ of the total activity of residual deposits from early April on). Iodine-131was the second leading contributor to the deposits' activity, accounting

\footnotetext{
${ }^{3}$ Iodine-132 is a by-product of the radioactive decay of telluride-132 and has a much shorter half-life, so these two radionuclides are always observed together in the environment at relatively close activity levels because the activities are nearly balanced. The same is true for barium- $140 /$ lanthane- 140 and telluride- $129 \mathrm{~m} /$ telluride- 129 , but for the latter the activity of telluride- 129 in a balanced state accounts for just $63 \%$ of the activity of its parent element (telluride- $129 \mathrm{~m}$ ), which has two of telluride- 129 in a balanceds
modes of radioactive decay.
} 


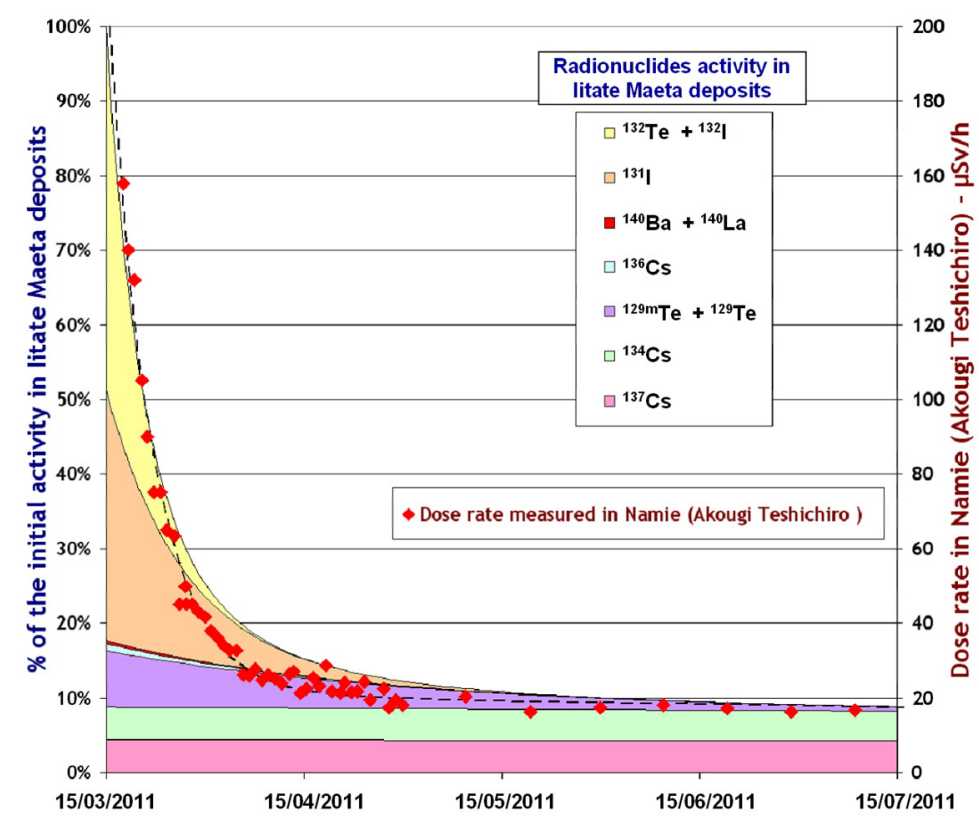

Figure 14-(Color online) Evolution in the relative activity of the main radionuclides in the fallout, deduced from the analysis performed by the IRSN on a topsoil sample collected on March 31, 2011, in Iitate Maeta and comparison with the evolution of the dose rate measured in Namie (values published by the MEXT).

for up to $40 \%$ at this location on March 23 (below we will see that the proportion of iodine-131 in the deposits varied depending on the place). Iodine-131 made up less than 5\% of the deposits' activity after May 1 and practically disappeared from the Japanese environment in the following weeks, except in the areas of the heaviest deposits, where it remained measurable until summer 2011 (by late June iodine-131's residual activity was 10,000 times lower than its initial activity).

Telluride-129m/telluride-129's contribution to the deposits grew from $8 \%$ on March 15 to $26 \%$ on April 15 before decreasing to less than 5\% of the deposits' residual activity by August 1, 2011.

Although cesium-136 and barium-140/lanthane-140 were detected in the environment in the weeks after the accident, at no time did they make a significant contribution to the deposits' total activity: a maximum of $1.7 \%$ and $0.7 \%$, respectively, in early April. By and large, all the radionuclides detected in low amounts, whatever their half-lives, contributed only marginally (less than $1 \%$ ) to the deposits' activity, and therefore to the population's exposure. 
Although cesium-134 and cesium-137 made up just 9\% of the initial activity, after May 15, 2011 they accounted for over $80 \%$ of residual deposits. That is why most of the maps of deposits published in Japan only show these two radionuclides. Because of its shorter half-life, cesium-134 decays at a fast rate: its contribution to the deposit peaked at $46 \%$ around mid-September 2011 and has been slowly decreasing since ( $43 \%$ one year after the accident); it will have dwindled to less than $5 \%$ by 2020, nine years after the accident. Cesium-137, then, determines the long-term consequences. Based on deposit maps published in Japan, the IRSN has estimated that the area where cesium-137's surface activity exceeds $10000 \mathrm{~Bq} / \mathrm{m}^{2}$ covers nearly $24000 \mathrm{~km}^{2}$, and that the area where it exceeds $600000 \mathrm{~Bq} / \mathrm{m}^{2}$ is probably approximately $600 \mathrm{~km}^{2}$, almost 20 times smaller than the area contaminated at an equivalent level by the Chernobyl accident.

Other radionuclides - silver-110m, niobium-95, strontium-89, strontium-90, plutonium, etc. - have been detected in deposits around the Fukushima plant but in much lower concentrations. Traces of plutonium attributable to the accident were found only in the area with the highest deposits, northwest of the damaged plant (MEXT, 2011a): the ${ }^{238} \mathrm{Pu} /{ }^{239+240} \mathrm{Pu}$ ratio is between 0.33 and 2.2, much higher than the ratio characteristic of fallout from atmospheric nuclear weapons tests (average value determined in Japan: 0.026). The measurements the IRSN performed on the soil sample from Iitate Maeta, provided by the ACRO, confirmed the findings published in Japan: the mass concentrations of ${ }^{238} \mathrm{Pu}$ and ${ }^{239+240} \mathrm{Pu}$ are 0.33 and $0.41 \mathrm{~Bq} /$ fresh $\mathrm{kg}$, respectively, yielding a $0.8{ }^{238} \mathrm{Pu} /{ }^{239+240} \mathrm{Pu}$ ratio, comparable with those determined based on findings published by the MEXT. The results attest that plutonium was released during the Fukushima accident; more specifically, the fact that all the values were obtained at points northwest of the main deposit area make it possible to attribute the plutonium to the releases from reactor 2, whose containment wall was damaged by overpressure on March 15. It is worth emphasizing that the released plutonium had a small environmental impact: the deposits measured in Japan are only a few $\mathrm{Bq} / \mathrm{m}^{2}$ at the most, much lower than those around the Chernobyl plant, where the surface activity of ${ }^{239+240} \mathrm{Pu}$ exceeded $3700 \mathrm{~Bq} / \mathrm{m}^{2}$ up to more than $30 \mathrm{~km}$ away and even reached several hundred thousand $\mathrm{Bq} / \mathrm{m}^{2}$ several kilometers from the plant.

Examination of the measurement results published in Japan shows that, generally, volatile radionuclides (iodine, cesium and telluride isotopes) were dominant in the initial deposits due to the accident. Low-volatility elements (barium, lanthane, silver, strontium, plutonium, etc.) account for less than $1 \%$ of the deposits' total activity. That is explained by release conditions during the accident (decompression of the three damaged reactors' containment), which were 


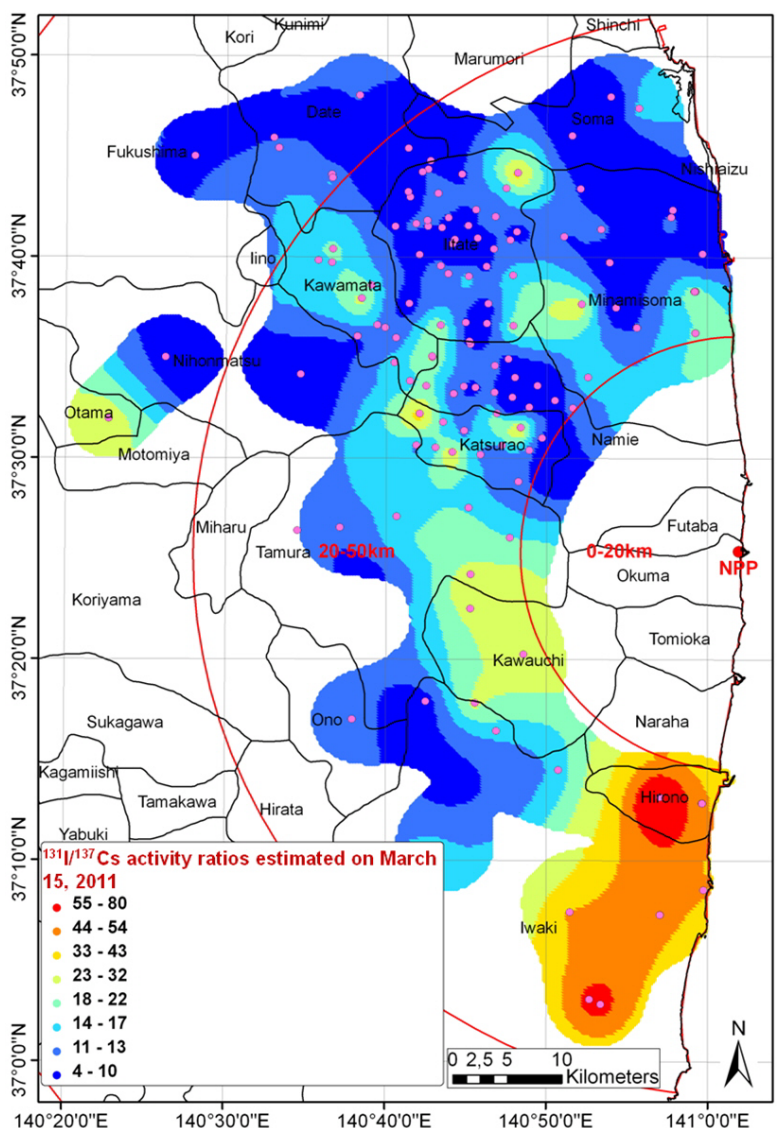

Figure 15 -(Color online) Map showing the distribution of the ratio of the mass activities of 1311/137Cs in the soils around the Fukushima Daiichi plant on March 15, 2011 (date of formation of the main fallout) obtained by geostatistical analysis of the measurement results published by the MEXT. The pink dots show the soil sampling stations.

very different from those occurring during the Chernobyl accident (explosion of the reactor core, which released large amounts of low- or non-volatile products).

Deposits outside the main deposit area northwest of the plant were smaller and had a different isotopic composition. A geostatistical analysis (Gonze et al., 2012; Métivier et al., 2012) of mass activity measurement results in soils published by the MEXT (160 unevenly distributed sampling sites in a semi-circle 20 to 80 kilometers around the damaged plant) reveals that the initial deposits were 
much higher in iodine-131 in the area south of the Fukushima Daiichi plant (the coastal area in the direction of Iwaki) than in the area northwest of it: the ${ }^{131} \mathrm{I} /{ }^{137} \mathrm{Cs}$ ratio of initial activities (reported on March 15, 2011) was close to 50 to the south, compared with eight to 12 in the northwest (Fig. 15). A similar tendency is observed for telluride- $129\left({ }^{129 \mathrm{~m}} \mathrm{Te} /{ }^{137} \mathrm{Cs}\right.$ ratio of $1.56 \pm 0.62$ to the northwest and $6.1 \pm 1.4$ to the south).

In the southern sector, where radioactive fallout was lower than in the northwest, a predominance of dry deposits, different physical-chemical forms of iodine (gas or aerosols) in the air at the time the deposit was formed, or an isotopic composition different from the releases concerned may explain the higher proportion of radioactive iodine.

This also means that if the deposits persisting south of the Fukushima Daiichi plant are relatively lower, the concentrations of radioactive iodine in the air may have been as high as they were in the northwest sector in the hours following the releases. This observation is consistent with the IRSN's estimates of doses potentially received during the March 12-25 release phase (Fig. 9), which indicate that they may have been high south of the plant, primarily due to the inhalation of radioactive iodine.

\subsection{Estimate of doses potentially received by the population exposed to radioactive deposits}

After the initial deposits formed during the dispersion of the atmospheric releases, people living in affected areas have been exposed to gamma radiation emitted by the radioactive deposit (external exposure). It is a continuous exposure for residents, modulated by travel, the time spent outdoors and the degree of protection afforded by the buildings in which they stay, which depends on their size and the density of construction materials (a small wooden house protects less from exterior radiation than a large concrete building).

Data on the radioactive deposits' characteristics and their spatial distribution published in Japan from April 2011 have made it possible to estimate projected doses due to external exposure to radioactive deposits, particularly those that the MEXT or IRSN published in 2011. Estimating the doses over a given period (one month, three months, one year, etc., after the accident began) takes several factors into account:

- the speed of the decrease in the ambient dose rate resulting from radioactive deposits, which depends on the deposits' initial isotopic composition (see above, Fig. 14); 
- the hypotheses on time spent outdoors and on the buildings' protection factor $(\boldsymbol{P F})$ (decrease in the interior dose rate compared with the rate measured outdoors). Different values were chosen by the IRSN (12 hours a day outdoors and $P F=0.3$ ) and MEXT (eight hours a day outdoors and $P F=0.4$ ), but in the end combining both parameters yields an equivalent result (daily reduction by a factor of 0.65 for the IRSN, and 0.6 for the MEXT).

These estimates are indicative and do not take account of the factors' variability, particularly lifestyle (time spent outdoors, protection provided by the various buildings occupied, movements, etc.) and the radioactive deposits' local heterogeneity ("hot spots"). For example, spending just four hours a day outdoors in the contaminated areas instead of eight hours can lower the dose by $20 \%$ or more, depending on the buildings' protective effect, compared with the value estimated by the MEXT.

By comparing the map of doses published by the MEXT with the map of surface activities of cesium-134 and cesium-137 deposits, it was possible to deduce a conversion factor between the dose from external exposure to deposits accumulated over the first year, and the surface activity of cesium-134 and cesium-137: $16.6 \mathrm{mSv}$ per $\mathrm{MBq} / \mathrm{m}^{2}$ of ${ }^{134+137} \mathrm{Cs}$.

As in the release phase, the radioactive deposits' dose kinetics changed over time. Immediately after forming on the night of March 15-16, the surface deposits mostly comprised short-lived radionuclides $\left({ }^{131} \mathrm{I},{ }^{132} \mathrm{Te} /{ }^{132} \mathrm{I}\right)$; by the end of one month, due to the radionuclides' rapid decay, the residual surface deposits' total activity accounted for just $15 \%$ of initial activity and the ambient dose rate measured over the same period in the same areas had decreased by as much (see Fig. 14). That is why, in compliance with the approach proposed by the French CODIRPA (Executive Committee for Post-accident Situation Management After a Nuclear Accident) (ASN, 2012), the IRSN calculated doses due to external exposure to deposits potentially received during the first months after their formation (i.e. from March 15 to April 15, 2011) and then over the next 12 months (from April 15, 2011 to April 15, 2012). The calculations were made based on the interpretation of the map of dose rates on April 24, 2011 published by the MEXT and by taking an isotopic composition of the deposits deduced from the source term estimated by the IRSN. The doses were calculated for a person assumed to stay $12 \mathrm{~h}$ /day outdoors and the remaining time inside a building with a protection factor of 0.3. The results of the estimates appear as iso-doses on the maps in Figure 16.

The maps show that in the first month after the deposits' formation, the population in an area surpassing the $20-\mathrm{km}$ evacuation zone, including parts of the 


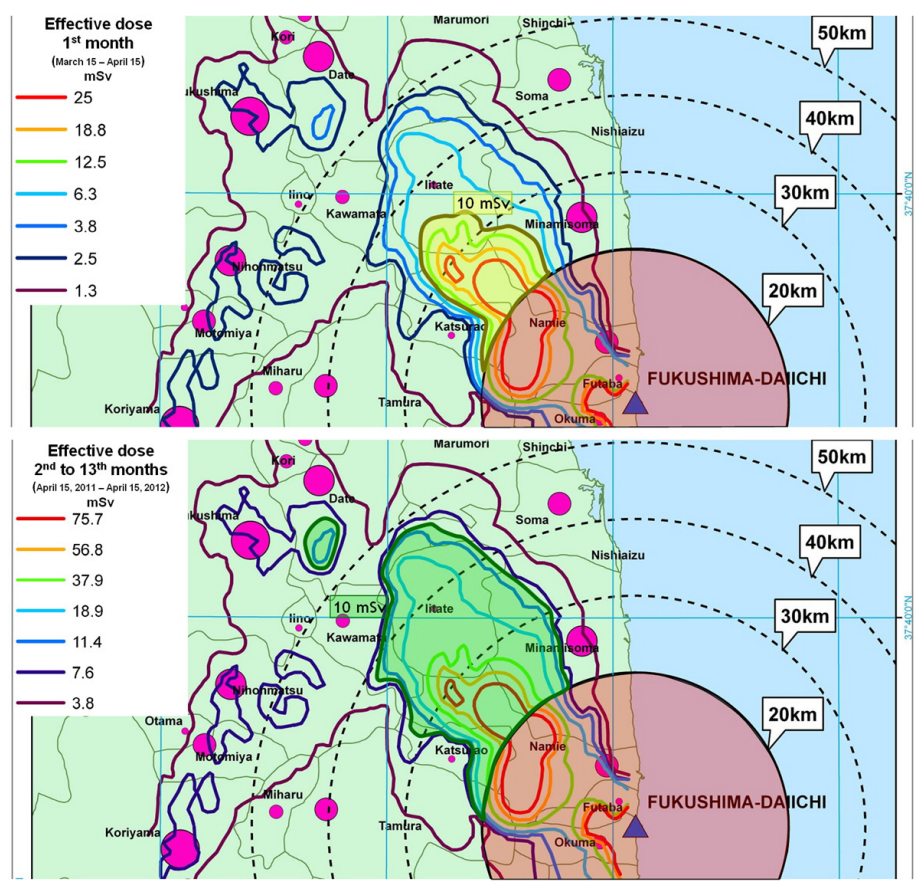

Figure 16-(Color online) Top: area (in yellow) where doses due to external exposure to radioactive deposits are likely to have been greater than $10 \mathrm{mSv}$ at the end of the first month following the formation of deposits in the Fukushima Prefecture. Bottom: area (in green) where doses due to external exposure to radioactive deposits are estimated to exceed $10 \mathrm{mSv}$ between April 15, 2011 and April 15, 2012 in the Fukushima Prefecture. Red circular area is the 20-km emergency evacuation zone set up during the accident.

towns of Minamisoma, Namie, Katsurao and Iitate, may have received a dose exceeding $10 \mathrm{mSv}$ (the guideline value in France for moving people in postaccident situations). The doses in this area may have exceeded $25 \mathrm{mSv}$, without taking into account doses due to exposure to the radioactive plume between March 12 and 25 (see Sect. 1.3 above) or to possible consumption of contaminated food. In the next 12 months (April 15, 2011-April 15, 2012), the areas where a potential dose due to external exposure to the deposits may have been above $10 \mathrm{mSv}$ are slightly larger than those identified for the previous period and, in addition to the above-mentioned towns, include the entire town of Iitate and parts of Soma and Date. Given the deposits' distribution, these areas are discontinuous (there is an isolated zone in Date). The projected doses in a significant part of the $20-\mathrm{km}$ emergency evacuation zone are high, justifying keeping this area in the exclusion zone. 
These estimates performed by the IRSN in May 2011 helped identify a first area where, in application of the CODIRPA's proposed protection strategy, early moving of resident people could have been justified, due to the level of doses potentially received by external exposure to the deposits. Afterward, given the projected doses over the following 12 months, complementary moving could have been extended to a wider area. Of course, such a strategy assumes that the deposits' area distribution and characteristics (isotopic composition) are known as early as possible in order to ensure the best possible protection of populations. The authorities in Japan implemented a different approach, based on forecasts of doses due to external exposure to the deposits over the course of the first year and taking a benchmark dosimetric value of $20 \mathrm{mSv}$ for this period, which led them to establish a "planned evacuation zone" (or "wider evacuation zone") on April 22, 2011 including the towns of Katsurao, Iitate, Namie and parts of Kawamata and Minamisoma. The evacuation took place in stages until August 18, 2011. Additional evacuations were decided on June 16, July 21 and August 2, 2011 for certain areas outside the zone (in Date and Minamisoma), where the local radiological dose was higher. This approach eventually led to gradual evacuation of population in areas that are practically the same as those shown on the maps in Figure 19.

\section{Conclusions and prospects}

A posteriori analysis of the Fukushima accident's sequence of events helps provide an overview of the various processes of contamination of Japan's terrestrial environment and resulting protection issues.

The radioactive plumes formed by the dispersion of the power plant's releases, which were discontinuous and occurred mainly before March 17, 2011, were the first exposure pathway. A theoretical estimate of the doses potentially received by the population exposed to the plumes (external exposure and inhalation) shows that the greatest impact was probably on the coastal areas several tens of kilometers north and south of the stricken plant.

The releases' complex sequences and the inaccuracy of meteorological data on this scale, in a quickly shifting meteorological context (particularly on March 15, 2011), make it tricky to estimate doses on the local scale.

It is worth noting that the areas where the radioactive deposits had the greatest impact, located northwest of the Fukushima plant, are not those where doses due to exposure to the plume were highest. This is explained by the influence of precipitation (rain or snow) causing these deposits on the night of March 15-16, whereas dry deposits, which were found in smaller amounts, accounted for most 
of the deposits in the areas where exposure to the plume was greater. The result is a wide disparity in the exposure pathways' contribution to the dose received during the accident phase depending on the place of residence.

In addition to exposure to the radioactive plume and gamma radiation emitted by the deposits, internal exposure through ingestion of contaminated food may have occurred, particularly in the first weeks after the accident. Estimating the doses requires having sufficiently complete data on the contamination of food produced (taking into account its evolution over time), the affected population's diets and the effective compliance with consumption and marketing restrictions the Japanese authorities prescribed after the accident. The IRSN has done specific work on this issue, which does not fall within the scope of the present article.

Some areas of Japan's terrestrial environment will be affected by long-lasting contamination, almost completely composed of radioactive cesium. In the absence of human intervention, the contamination is likely to decrease only slowly due to radioactive decay and migration of radionuclides in the soil. The nature of the radiological hazard has changed since the accident and early post-accident phase. The persistence of cesium in surface deposits will result in chronic exposure of the population, but the dose levels will be significantly lower than those to which it was potentially exposed in the days and weeks following the accident.

Japan has begun to reclaim its contaminated areas, but the process is likely to be long and costly. It will probably be difficult to restore the most contaminated areas, in terms not only of radiation protection but also of image and living conditions.

\section{REFERENCES}

ASN (2012) Éléments de doctrine pour la gestion post-accidentelle d'un accident nucléaire - Version finale du 5 octobre 2012. Comité Directeur pour la gestion de la phase post-accidentelle d'un accident nucléaire (CODIRPA) (http://www.asn.fr/index.php/Bas-de-page/Sujet-Connexes/Gestionpost-accidentelle/Comite-directeur-gestion-de-phase-post-accidentelle/Elements-de-doctrinepour-la-gestion-post-accidentelle-d-un-accident-nucleaire-5-octobre-2012).

Corbin D., Denis J. (2012) Évaluations des rejets atmosphériques associés à l'accident de Fukushima. Rapport IRSN/PSN-RES/SAG/2012-00347 (available upon request at http://www.irsn.fr/ EN/ Contact/ Pages/Question.aspx).

Gonze M.A., Simon-Cornu C., Métivier J.M., Garcia-Sanchez L., Mourlon C., Parache V. (2012) Landscape-level Model Predictions of ${ }^{131} \mathrm{I},{ }^{134} \mathrm{Cs}$ and ${ }^{137} \mathrm{Cs}$ transfer through terrestrial systems in the 80-km Fukushima-Daiichi area using the Symbiose Platform. IRPA, May 2012, Glasgow (available on website irpa13glascow.com or http://www.irsn.fr/FR/Larecherche/publicationsdocumentation/Publications_documentation/BDD_publi/DEI/Documents/IRPA13-IRSN-posterM-A-Gonze-P12-23.pdf).

IAEA (2006) Environmental consequences of the Chernobyl accident and to their remediation: twenty years off experiment. Report of the Chernobyl Forum Expert Group 'Environment', International Atomic Energy Agency. 
THE IRSN'S EARLIEST ASSESSMENTS OF THE FUKUSHIMA ACCIDENT'S CONSEQUENCES

IRSN (2011) Première évaluation de la radioactivité rejetée par la centrale de Fukushima Dai-ichi jusqu'au 22 mars 2011. Note d'information IRSN.fr, 22 mars 2011 (irsn.fr or available upon request at http://www.irsn.fr/EN/Contact/Pages/Question.aspx)

Korsakissok I., Didier D., Mathieu A., Quélo D., Groell J., Quentric E., Tombette M., Benoit J.P., Saunier O. (2012) Evaluation of the atmospheric releases of the Fukushima accident and their consequences. Rapport IRSN/PRP-CRI/SESUC/2012-35 (available upon request at http://www.irsn.fr/EN/Contact/Pages/Question.aspx).

Mathieu A., Korsakissok I., Quélo D., Groëll J., Tombette M., Didier D., Quentric E., Saunier O., Benoît J.-P., Isnard O. (2011) Atmospheric Dispersion and Deposition of Radionuclides from the Fukushima Daiichi Nuclear Power Plant Accident, Elements 8 (3).

Métivier J.M, Baccou J., Gonze M.A., Durenne A. (2012) Combining kriging with non-systematic error and lognormal kriging for contamination mapping around Fukushima Daiichi. GeoEnv, September 2012, Valencia (Spain).

MEXT (2011a) Results of the Nuclide Analysis of Plutonium and Strontium by MEXT. MEXT Report, Ministry of Education, Culture, Sport, Sciences and Technology - Japan, September 30, 2011 (http://radioactivity.mext.go.jp/en/contents/5000/4167/24/1750_093014.pdf).

MEXT (2011b) Results of the Fourth Airborne Monitoring Survey by MEXT. MEXT Report, Ministry of Education, Culture, Sport, Sciences and Technology - Japan, December 16, 2011 (http://radioactivity.mext.go.jp/en/contents/4000/3179/24/1270_1216.pdf).

NISA (2011) Regarding the Evaluation of the Conditions on Reactor Cores of Unit 1, 2 and 3 related to the Accident at Fukushima Dai-ichi Nuclear Power Station, TEPCO, Nuclear and Industrial Safety Agency.

Quélo D., Krysta M., Bocquet M., Isnard O., Minier Y., Sportisse B. (2007) Validation of the Polyphemus platform on the ETEX, Chernobyl and Algeciras cases, Atmos. Environ. 41, 5300-5315.

Saunier O., Mathieu A., Didier D., Tombette M., Quélo D., Winiarek V., Bocquet M. (2012) Using gamma dose rate monitoring with inverse modeling techniques to estimate the atmospheric release of a nuclear power plant accident: application to the Fukushima case. Proc. Int. International Meeting on Severe Accident Assessment and Management: Lessons Learned from Fukushima Dai-ichi, San Diego, California, November 11-15, 2012, American Nuclear Society (2012).

Soulhac L. and Didier D. (2008) Projet pX, note de principe pX 1.0. Note technique IRSN/DEI/SESUC/08-39 (available upon request at http://www.irsn.fr/EN/Contact/Pages/ Question.aspx). 